\title{
Proceeding Paper \\ Unravelling Plant-Pathogen Interactions: Proximal Optical Sensing as an Effective Tool for Early Detect Plant Diseases ${ }^{\dagger}$
}

\author{
Mafalda Reis-Pereira ${ }^{1,2, * \mathbb{D}}$, Rui C. Martins ${ }^{3, *}$, Aníbal Filipe Silva ${ }^{1,3} \mathbb{D}$, Fernando Tavares ${ }^{1,4}$ (D) Filipe Santos ${ }^{2} \mathbb{D}$ \\ and Mário Cunha $1,2, *$ (D)
}

1 Faculty of Sciences, University of Porto (FCUP), Rua Campo Alegre, s/n, 4169-007 Porto, Portugal; afilipe.silva@fc.up.pt (A.F.S.); ftavares@fc.up.pt (F.T.)

2 Centre of Robotics in Industry and Intelligent Systems, INESC TEC, Dr. Roberto Frias, 4200-465 Porto, Portugal; filipe.n.santos@inesctec.pt

3 Centre for Applied Photonics, INESC TEC, Faculty of Sciences, University of Porto, Rua do Campo Alegre, s/n, 4169-007 Porto, Portugal

4 Research Centre in Biodiversity and Genetic Resources (CIBIO-InBIO), Rua Padre Armando Quintas, ${ }^{\circ}$ 7, 4485-661 Vairão, Portugal

* Correspondence: mafalda.r.pereira@inesctec.pt (M.R.-P.); rui.c.martins@inesctec.pt (R.C.M.); mario.cunha@inesctec.pt (M.C.)

+ Presented at the 1st International Electronic Conference on Chemical Sensors and Analytical Chemistry, 1-15 July 2021; Available online: https:/ / csac2021.sciforum.net/.

check for updates

Citation: Reis-Pereira, M.;

Martins, R.C.; Silva, A.F.; Tavares, F.; Santos, F.; Cunha, M. Unravelling Plant-Pathogen Interactions: Proximal Optical Sensing as an Effective Tool for Early Detect Plant Diseases. Chem. Proc. 2021, 5, 18. https://doi.org/10.3390/CSAC202110560

Academic Editor: Elena Benito-Peña

Published: 1 July 2021

Publisher's Note: MDPI stays neutral with regard to jurisdictional claims in published maps and institutional affiliations.

Copyright: (c) 2021 by the authors. Licensee MDPI, Basel, Switzerland. This article is an open access article distributed under the terms and conditions of the Creative Commons Attribution (CC BY) license (https:/ / creativecommons.org/licenses/by/ $4.0 /)$.

\begin{abstract}
This study analyzed the potential of proximal optical sensing as an effective approach for early disease detection. A compact, modular sensing system, combining direct UV-Vis spectroscopy with optical fibers, supported by a principal component analysis (PCA), was applied to evaluate the modifications promoted by the bacteria Xanthomonas euvesicatoria in tomato leaves (cv. cherry). Plant infection was achieved by spraying a bacterial suspension $\left(10^{8} \mathrm{CFU} \mathrm{mL}{ }^{-1}\right)$ until run-off occurred, and a similar approach was followed for the control group, where only water was applied. A total of 270 spectral measurements were performed on leaves, on five different time instances, including pre- and post-inoculation measurements. PCA was then applied to the acquired data from both healthy and inoculated leaves, which allowed their distinction and differentiation, three days after inoculation, when unhealthy plants were still asymptomatic.
\end{abstract}

Keywords: plant disease detection; plant pathology; proximal sensing; spectroscopy; precision agriculture; principal component analysis

\section{Introduction}

Biotic agents, specifically pests and pathogens, cause significant losses in crop yields, with levels that can range between $20 \%$ and $40 \%$ [1]. Chemical phytosanitary products are usually applied to prevent and combat these organisms. However, their usage can negatively impact the environment, mainly when applied to treat plant diseases that appear suddenly and spread to large scales [2].

Nowadays, phytopathology methods are considered major challenges because, to be implemented, they often rely on the presence of indicator visible signs of the infection (disease symptoms), which frequently only manifest themselves at the middle to late stages of the process, compromising the effectiveness of phytosanitary measures [3]. An example is the scouting technique, which involves inspecting a crop field to detect and identify infected plant through disease symptoms [4]. Despite being extremely useful, this approach requires specialized trained observers (who must be capable of identifying disease symptoms and distinguishing them from those caused by other abiotic stresses (e.g., nutritional and physiological disorders)), and can be labor-intensive, time-consuming, and expensive [5-11]. Moreover, this approach can be an inefficient in the early stages of the infection and on large areas. Other strategies consist of laboratory-based techniques, 
namely serological and molecular tests, largely used due to their sensitivity, accuracy, and effectiveness. They include enzyme-linked immunosorbent assay (ELISA) and polymerase chain reaction (PCR) methods, being the first serological approach based on protein in the detection of causative diseases and the second molecular technique based on the DNA sequence of the pathogen. Their development boosted plant disease diagnosis, since they allow the simultaneous processing of several samples and perform a precise pathogen identification. Furthermore, PCR enables the detection of pathogens that have not been cultured. Nevertheless, these procedures present some limitations, especially in the early phase of the infection process, due to the uneven spread of pathogens inside plants, compromising their effectiveness in analyzing asymptomatic samples [9,12-14]. Other drawbacks can also be enumerated. They require several hours to be completed, require the realization of detailed sampling procedures, and destructive sample preparation, not allowing a follow-up of the disease progression $[12,13]$.

Therefore, the necessity of developing fast, accurate, and selective in vivo techniques for plant disease detection arises. These innovative approaches must provide complementary information to the current methods applied in the phytopathology field and combine with them. Several non-invasive methods have been developed in the last decade, which proved to be sensitive, consistent, standardize, rapid, cost-effective, and have highthroughput [15]. Hyperspectral spectroscopy (HS) is one of them and seems to be effective in estimating a wide variety of plant chemical, biophysical, and metabolic traits in living tissue [16-22], namely foliar structure, plant chemical composition, water concentration, and metabolic status [23]. Through spectral measurements in the visible (Vis, 400-700 nm), nearinfrared (NIR, 700-1100 nm), and shortwave infrared wavelengths (SWIR, 1100-2500 nm), this approach assesses changes in optical properties of leaves, which derive from interactions between light, chemical bonds, and cellular structure [24]. Briefly, modifications in plants' reflectance in the Vis range are mostly related to pigment concentration and physiological processes, such as photosynthesis. In turn, changes in the NIR are correlated with leaf structure and internal scattering processes. The SWIR region is affected by leaf structural and chemical composition (including lignins and proteins), as well as water content [25-29].

Since phytopathogens induce physiological, biochemical, and structural changes in host plants, HS seems to be promising in plant disease detection, identification, and quantification [30-38]. Hyperspectral sensors can be used alone or mounted in different platforms, allowing the performance of mapping, monitoring, scouting, and application tasks [2]. Their flexibility allows them to assess leaf, single-plant, canopy (proximal sensing), and even plot and regional scales (remote sensing) [2]. Some examples, sorted by measurement scale, include handheld sensors, rail systems, vehicle, and tractor-mounted systems, drones UAVs, as well as aircrafts and satellites [39].

Despite the possibilities provided by these optical devices for simple, rapid, nondestructive disease detection and identification, its application is still very limited, due to the scarcity of extensive agronomic and phytopathological studies aiming to explore their full potential. Their technology readiness levels (TRL) are close to TRL3 (analytical and experimental critical function, and/or characteristic proof-of-concept) [40]. Hence, this study aimed to evaluate the potential of UV-Vis spectroscopy to detect diseased tomato leaves and discriminate between healthy and infected leaves, through a multitemporal approach. Furthermore, the capability of this technology in detecting changes in the reflectance spectrum of infected leaves was analyzed, before the first symptoms became visible.

\section{Materials and Methods}

\subsection{Experimental Design}

Tomato (Solanum lycopersicum L.) plants, of the cultivar cherry, were grown in $200 \mathrm{~mL}$ pots containing a commercial potting substrate, in a walk-in plant growth chamber under controlled conditions (temperature of $25-27{ }^{\circ} \mathrm{C}$, humidity of approximately $60 \%$, and 
photoperiod of $12 / 12 \mathrm{~h}$ ). Plants were divided into two groups, one of them being inoculated with Xanthomonas euvesicatoria LMG 905 (Xeu) bacteria and the other being treated with sterile distilled water only (control group, Con). Plants were inoculated in the laboratory, at the growth stage of 5-6 fully expanded leaves, by spraying until they became fully wet, and run-off occurred. The bacterial suspensions used for these inoculation assays consisted of $1 \times 10^{8}$ cells $/ \mathrm{mL}$. They were prepared from a 48 hour-old culture, grown on YDC medium (yeast extract, $10.0 \mathrm{~g}$; dextrose, $20.0 \mathrm{~g} ; \mathrm{CaCO}_{3}, 20.0 \mathrm{~g}$; agar, $15.0 \mathrm{~g}$; distilled water up to $1.0 \mathrm{~L}$ ). The inoculated plants were then covered with transparent polythene bags for $48 \mathrm{~h}$ to increase the relative humidity that fosters bacterial entry into plant tissues through natural openings, such as stomata [41]. Plants were monitored daily for symptom development for 5 days.

At the same time, to verify if the bacteria cultures used in these inoculation tests were viable, $20 \mu \mathrm{L}$ of Xeu solution were cultured in different Petri dishes containing YDC media. After $48 \mathrm{~h}$, it was possible to observe the bacteria growth in both nutrient media, proving that bacteria were viable at inoculation.

\subsection{Spectral Measurements}

Hyperspectral data were collected in vivo from the adaxial side of healthy and infected tomato plant leaves, using a compact benchtop system consisting of a D2 (deuterium) light source (Ocean Optics, model DH-2000-BAL, Ostfildern, Germany), spectrometer (Ocean Optics, model HR4000, Ostfildern, Germany), transmission optical fiber bundle (UV), and stainless-steel slitted reflection probe for sample measurement. The spectrometer operated in the 195-1100 nm wavelength range, with a high spectral response and optical resolution of $0.025 \mathrm{~nm}$ (full width at half maximum-FWHM). The measurements were carried out using an experimental setup in the laboratory. A LED light source was placed beneath the leaf and provided homogeneous illumination to its entire surface. The light signal from the sample analyzed was guided to the entrance lens of the spectrometer by the fiber-optic cable placed perpendicularly $1 \mathrm{~cm}$ above the measured surface. Specialized software was used for data acquisition and processing. Data acquisition was performed with 10 scans for an integration period of $60 \mathrm{~ms}$, in three leaves per plant, on nine locations on each leaf.

\subsection{Data Pre-Processing}

Spectral pre-processing was performed, in order to remove possible artifacts, e.g., baseline shifts, Mie and Rayleigh scattering, and stray light. Also, a pretreatment with a fast fourier transform (FFT) was carried out on spectral data to smooth/denoise it. FFT is an algorithm that computes the discrete Fourier transform (DFT) of a sequence or its inverse (IDFT). Fourier analysis converts a signal from its original domain (often time or space) to a representation in the frequency domain and vice versa. The DFT is obtained by decomposing a sequence of values into components of different frequencies [42]. Spectral data pre-processing was performed with RStudio software.

\subsection{Data Processing-Analytical Techniques}

Spectral data was subjected to a principal component analysis (PCA), a multivariate data analysis technique was used to reduce the dimensionality, while preserving its structure by projecting it into a new coordinate system. This technique allows the preservation of the total variance of the dataset and minimizes the mean square approximate errors. PCA uses eigenvectors and eigenvalues to define the reduced subspace (representing the original coordinate system). It originates principal components (PC), which are linear combinations of interrelated variables. $\mathrm{PC} 1$ accounts for the maximum possible proportion of the variance information of the original dataset (explained by the eigenvalue), and subsequent principal components (PC2, PC $3, \ldots$ ) account for the maximum proportion of the unexplained residual variance, and so forth [43,44].

Contigous hyperspectral wavebands present redundant information [45]. The application of a PCA allows the transformation of this type of high-dimensional data into a few 
wavebands that contain most of the information in the original bands. The importance of these hyperspectral bands in each PC is then established based on the magnitude of eigenvectors or factor loadings for crop biophysical and biochemical traits, being that the higher the eigenvector, the higher is the importance of the band. So, PCA allows the selection of the best wavebands to model biophysical and biochemical quantities and the elimination of redundant bands (by highlighting the main bands) [46].

\section{Results}

The spectral response properties of tomato leaves to the stress caused by Xanthomonas euvesicatoria LMG 905 is very important for discriminating bacterial infection levels in precise pest management using hyperspectral proximal sensing data. The averaged raw spectral curves of healthy and diseased tomato leaves were slightly different in some spectral ranges, namely through the visible region of the wavelength spectrum $(\sim 480-680 \mathrm{~nm})$ (please refer to Figure 1) Similarly, the spectral measurements assessed on infected leaf tissue presented a decrease in signal intensity throughout the sampling period (24-144 h), which accompanied the appearance of the first visual symptoms of the disease after $72 \mathrm{~h}$.

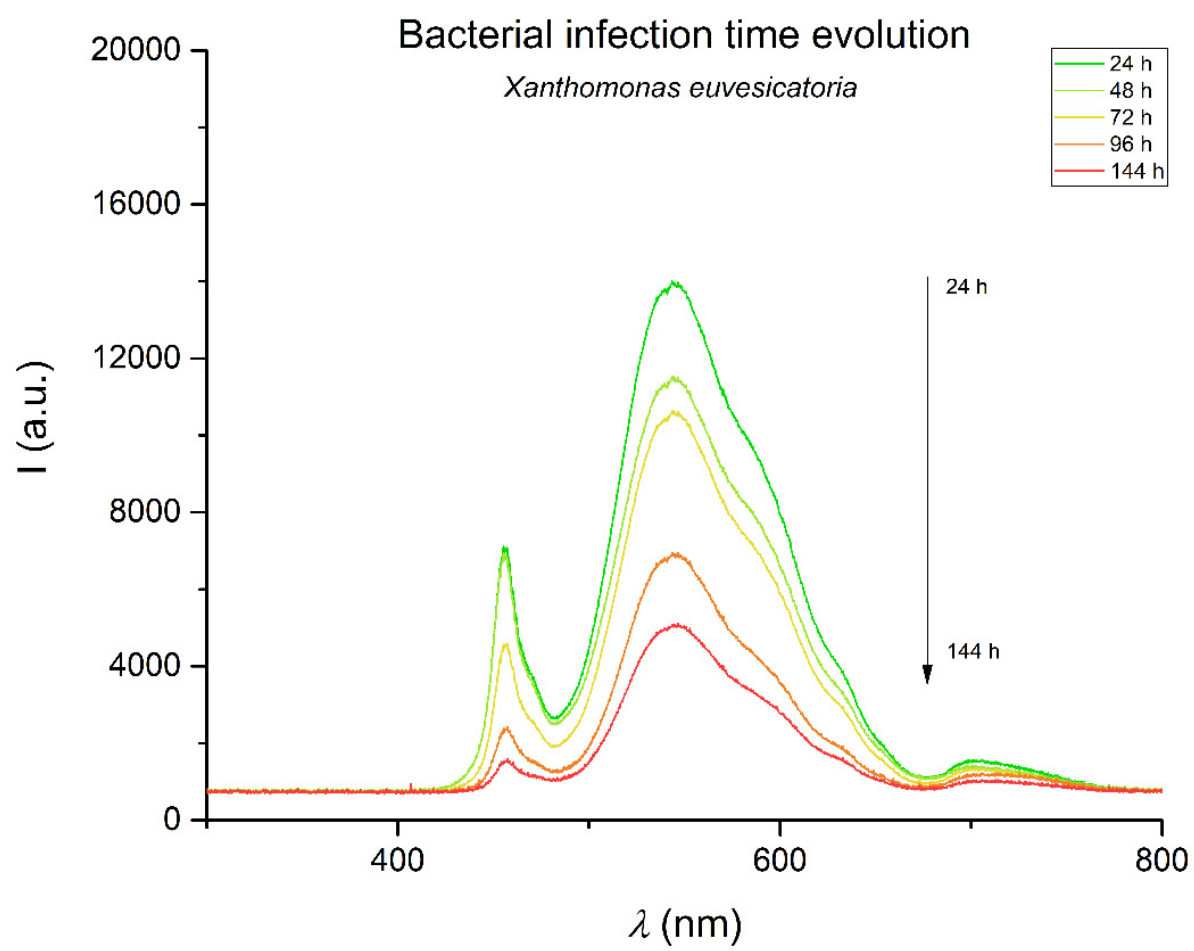

Figure 1. Spectral measurement curve evolution for tomato leaves inoculated with bacteria Xanthomonas euvesicatoria LMG 905, within the sampling period (24-144 h). Leaf spectral curves were assessed in vivo on the adaxial side of fully expanded leaves, on the spectral region from 195 to $1100 \mathrm{~nm}$.

Figure 2 presents the principal components (PC) Gabriel plot for the healthy (Con) and diseased (Xeu) leaves spectra, three days after inoculation (before the appearance of the first symptoms). The PCA algorithm has obtained two PCs, accounting for $99.6 \%$ of the total variance. PC1 $(94.3 \%)$ discriminates the effects on the variance of these two types of tomato leaves, which is more evident in PC2 (5.3\%). 

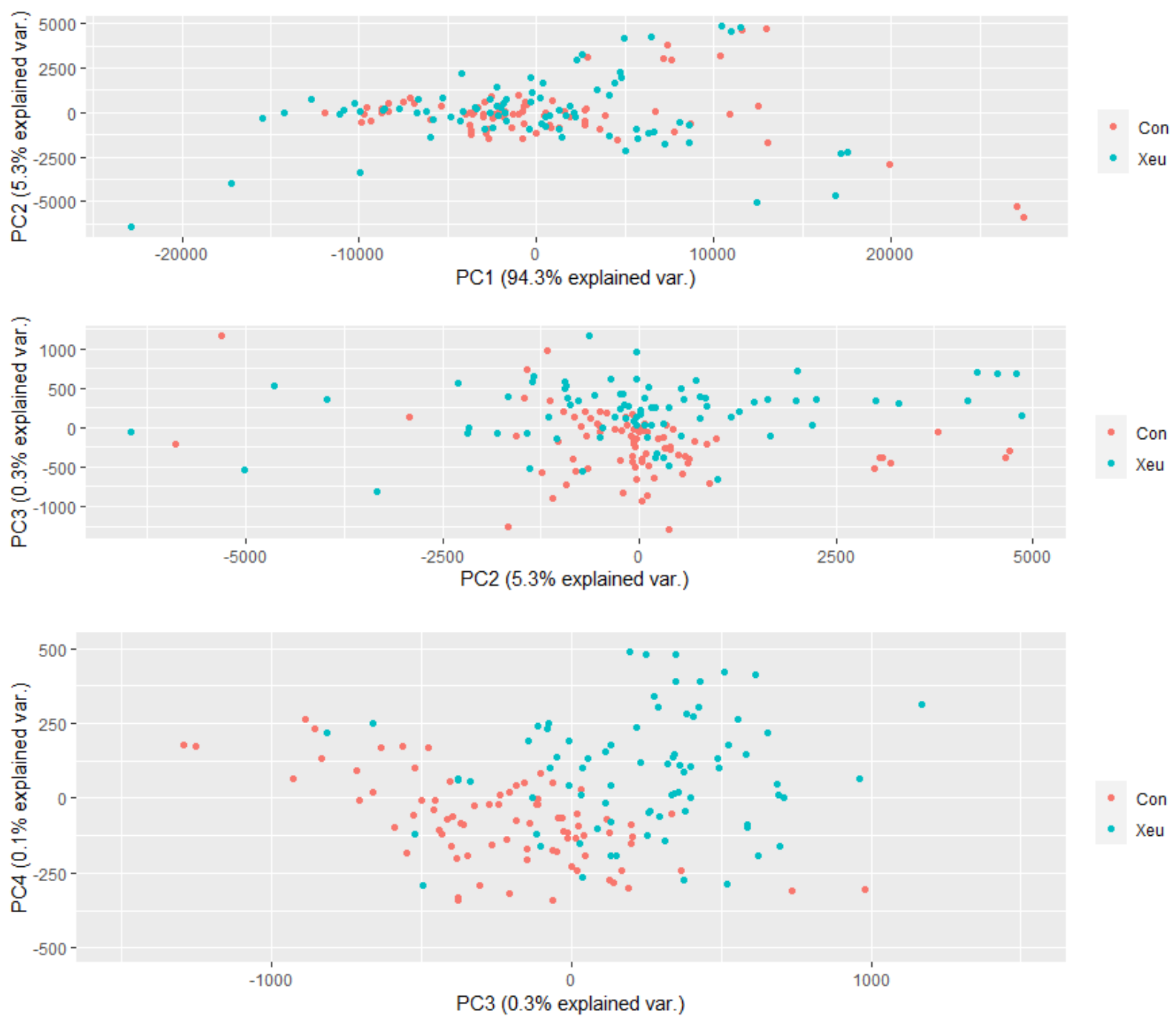

Figure 2. Gabriel plot of PC1, PC2, and PC3 resulting from the PCA of the dataset three days after inoculation (all leaves were asymptomatic, showing no symptoms of the disease caused by Xanthomonas euvesicatoria LMG 905).

The wavelengths that have a higher contribution in these PC are in the interval of $\sim 454-654 \mathrm{~nm}$ (visible range of the wavelength spectrum). The ones between $\sim 492-510 \mathrm{~nm}$ (essentially the blue region of the electromagnetic spectrum) explain $30 \%$ of the variance of the PC1, whereas 454-461 nm (blue region) explain $40 \%$ of the variance of the PC2 and $50 \%$ of the PC3. In all the first four dimensions of this analysis, the wavelengths ranging from approximately $445-480 \mathrm{~nm}$ (blue) and 580-700 nm (red) were the ones that explain most of the variance of the data.

This evidence can be related to the symptoms caused by Xeu, since these bacteria cause small, brown, angular lesions on leaves (which can be surrounded by a yellow halo with time), affecting the levels of photosynthetic pigments (contributing especially to the reduction of the chlorophyll levels, whose absorption features are more evident in the blue and red ranges of the Vis spectral region), cellular content, and structural arrangement.

\section{Discussion}

The spectral behavior of tomato plants depends on their biochemical and structural profile. In brief, plants' spectral signature in the visible spectral region $(400-700 \mathrm{~nm})$ depends mainly on the content of photosynthetic pigments. These compounds are good absorbers of red and blue wavelengths. Of the major pigments, Chlorophyll a (Chl a) has maximum absorption in the 410-430 and 600-690 nm regions, whereas Chlorophyll b 
(Chl b) has maximum absorption in the 450-470 $\mathrm{nm}$ range. In healthy plants, chlorophyll concentration is approximately ten times higher than that of other pigments, thus masking out the specific absorption features of these compounds. The green part of the spectrum, on the other hand, is less strongly absorbed, resulting in a reflectance peak in the green domain (at about $550 \mathrm{~nm}$ ) [25]. Hence, when a light source illuminates healthy plants, they will preferentially absorb red and blue wavelengths, being the green part of the incident light less absorbed and, consequently, more reflected, leading to their green appearance [26]. In the NIR region, the plants' spectral response is related to their structure, structural components, and internal scattering processes. Likewise, the SWIR region is also affected by leaf structural and chemical composition (including the action of lignin's and proteins) and water content [25-29].

Since phytopathogens cause changes in plants' biochemical and structural composition, affecting the levels of photosynthetic pigments and structural elements, tracking changes in plants' spectral behavior can allow an indirect analysis of their phytosanitary status. Generally, unhealthy plants have more reflection in the red region and lower reflectance in the NIR region. Briefly, stress usually promotes an increase of reflectance over the whole spectrum, since it causes a rapid decrease of chlorophylls, which increases reflectance in the Vis range and exposes the absorption characteristics of other pigments, such as carotenoids (responsible for the yellowing of the leaves) and xanthophylls (responsible for the reddening of the leaves). With continuing stress, leaf structures decompose, resulting in extra intra-leaf scattering and an increased NIR signal. At the same time, concentrations of brown pigments, which absorb radiance in the Vis and at the onset of the NIR, can increase leading to a flattening of the red edge. Absorption in the SWIR decreases, due to reduced leaf moisture. With a decay of the leaf tissue, the absorption features characteristics of healthy plants gradually disappear [47].

Our findings seem to be in accord with the previous information, showing evidence that UV-Vis spectroscopy can be suitable for plant disease assessment in laboratory conditions. Data collected in a randomized experimental design, combined with a PCA, allowed the discrimination of healthy and diseased tomato leaves, even at the third day after bacteria inoculation, when no visual symptoms were observable. Most of the variance of the data can be comprised with the first four PCs. In all of them, the wavelengths that explain most of the variance of the data ranged from approximately $445-480 \mathrm{~nm}$ (blue) and $580-700 \mathrm{~nm}$ (red), which was expected, since Xanthomonas euvesicatoria causes tissue lesions, degrading the chlorophylls levels and affecting their absorption features in these spectral regions.

Therefore, our results can be related to those obtained in different research, where sensor-based approaches proved to be capable of assessing modifications in plants' spectral behavior, allowing the detection, identification, and quantification of different types of plant diseases [44,48-51]. They involve the capture and analysis of the optical properties of plants, within different regions of the electromagnetic spectrum and their relationship with modifications in plant physiology, namely alterations in tissue color, structural composition, and transpiration rate [19]. These non-invasive methods have been explored in the last decade, presenting the benefits of being sensitive, consistent, standard, high-throughput, rapid, and cost-effective [47], surpassing the limitations of the current methods used in plant disease detection.

\section{Conclusions}

The present study suggests that UV-Vis spectroscopy can be a potential tool for the early detection of plant diseases under laboratory conditions, even when unhealthy plants are asymptomatic. Despite these findings, its application is still very limited, due to the scarcity of comprehensive agronomic and phytopathological studies aiming to explore their full potential, as well as the development of applied advanced statistical approaches for data analysis. More research is necessary, especially in field conditions, where more external factors have to surpass, including atmospheric, edaphic, and biotic conditions. 
Future research should also include more stress levels to discriminate not only healthy leaves from the diseased ones but also different levels of disease severity.

Author Contributions: Conceptualization, M.R.-P., R.C.M., A.F.S., F.T., F.S. and M.C.; methodology, M.R.-P., R.C.M., A.F.S., F.T., F.S. and M.C.; validation, M.R.-P., R.C.M. and M.C.; formal analysis, M.R.-P., R.C.M. and M.C.; investigation, M.R.-P., R.C.M. and M.C.; resources, R.C.M., F.T., F.S. and M.C.; data curation, M.R.-P. and R.C.M.; writing—original draft preparation, M.R.-P.; writing—review and editing, R.C.M., A.F.S., F.T., F.S. and M.C.; supervision, F.T., F.S. and M.C.; funding acquisition, M.R.-P., R.C.M., A.F.S., F.T., F.S. and M.C. All authors have read and agreed to the published version of the manuscript.

Funding: Mafalda Reis-Pereira and Aníbal Filipe Silva were supported by fellowships from Fundação para a Ciência e a Tecnologia (FCT), with the references SFRH/BD/146564/2019 and DFA/BD/9136/2020, respectively. Rui C. Martins acknowledges Fundação para a Ciência e Tecnologia (FCT) research contract grant (CEEIND/017801/2018). This research was supported by the project 'SpecTOMMetabolomics Tomography Spectroscopy System', University of Porto, Fundação Amadeus Dias, and Santander-Universities Grant.

Acknowledgments: Mafalda Reis-Pereira and Aníbal Filipe Silva were supported by fellowships from Fundação para a Ciência e a Tecnologia (FCT), with the references SFRH/BD/146564/2019 and DFA/BD/9136/2020, respectively. Rui C. Martins acknowledges Fundação para a Ciência e Tecnologia (FCT) research contract grant (CEEIND/017801/2018). This research was supported by the project 'SpecTOM-Metabolomics Tomography Spectroscopy System', University of Porto, Fundação Amadeus Dias, and Santander-Universities Grant.

Conflicts of Interest: The authors declare no conflict of interest.

\section{References}

1. Savary, S.; Ficke, A.; Aubertot, J.-N.; Hollier, C. Crop losses due to diseases and their implications for global food production losses and food security. Food Secur. 2012, 4, 519-537. [CrossRef]

2. Zhang, N.; Yang, G.; Pan, Y.; Yang, X.; Chen, L.; Zhao, C. A review of advanced technologies and development for hyperspec-tralbased plant disease detection in the past three decades. Remote Sens. 2020, 12, 3188. [CrossRef]

3. Lowe, A.; Harrison, N.; French, A.P. Hyperspectral image analysis techniques for the detection and classification of the early onset of plant disease and stress. Plant Methods 2017, 13, 1-12. [CrossRef]

4. Parker, S.R.; Shaw, M.W.; Royle, D.J. The reliability of visual estimates of disease severity on cereal leaves. Plant Pathol. 1995, 44, 856-864. [CrossRef]

5. Mahlein, A.-K. Plant Disease Detection by Imaging Sensors-Parallels and Specific Demands for Precision Agriculture and Plant Phenotyping. Plant Dis. 2016, 100, 241-251. [CrossRef]

6. Liaghat, S.; Ehsani, R.; Mansor, S.; Shafri, H.Z.; Meon, S.; Sankaran, S.; Azam, S.H. Early detection of basal stem rot disease (Ganoderma) in oil palms based on hyperspectral reflectance data using pattern recognition algorithms. Int. J. Remote Sens. 2014, 35, 3427-3439. [CrossRef]

7. Pérez, M.R.V.; Mendoza, M.G.G.; Elías, M.G.R.; González, F.J.; Contreras, H.R.N.; Servin, C.C. Raman Spectroscopy an Option for the Early Detection of Citrus Huanglongbing. Appl. Spectrosc. 2016, 70, 829-839. [CrossRef]

8. Ali, M.M.; Bachik, N.A.; Muhadi, N.A.; Yusof, T.N.T.; Gomes, C. Non-destructive techniques of detecting plant diseases: A review. Physiol. Mol. Plant Pathol. 2019, 108. [CrossRef]

9. Sankaran, S.; Mishra, A.; Ehsani, R.; Davis, C. A review of advanced techniques for detecting plant diseases. Comput. Electron. Agric. 2010, 72, 1-13. [CrossRef]

10. Chen, W.-L.; Lin, Y.-B.; Ng, F.-L.; Liu, C.-Y.; Lin, Y.-W. RiceTalk: Rice Blast Detection Using Internet of Things and Artificial Intelligence Technologies. IEEE Internet Things J. 2020, 7, 1001-1010. [CrossRef]

11. Khaled, A.Y.; Aziz, S.A.; Bejo, S.K.; Nawi, N.M.; Seman, I.A.; Onwude, D.I. Early detection of diseases in plant tissue using spec-troscopy-applications and limitations. Appl. Spectrosc. Rev. 2018, 53, 36-64. [CrossRef]

12. Fang, Y.; Ramasamy, R.P. Current and Prospective Methods for Plant Disease Detection. Biosensors 2015, 5, 537-561. [CrossRef] [PubMed]

13. Martinelli, F.; Scalenghe, R.; Davino, S.; Panno, S.; Scuderi, G.; Ruisi, P.; Villa, P.; Stroppiana, D.; Boschetti, M.; Goulart, L.R.; et al. Advanced methods of plant disease detection. A review. Agron. Sustain. Dev. 2015, 35, 1-25. [CrossRef]

14. Moghadam, P.; Ward, D.; Goan, E.; Jayawardena, S.; Sikka, P.; Hernandez, E. Plant Disease Detection Using Hyperspectral Imaging. In Proceedings of the 2017 International Conference on Digital Image Computing: Techniques and Applications (DICTA), Sydney, Australia, 29 November-1 December 2017; Volume 2017, pp. 1-8.

15. Golhani, K.; Balasundram, S.K.; Vadamalai, G.; Pradhan, B. A review of neural networks in plant disease detection using hyper-spectral data. Inf. Process. Agric. 2018, 5, 354-371. 
16. Zhao, D.; Reddy, K.R.; Kakani, V.G.; Read, J.J.; Carter, G.A. Corn (Zea mays L.) growth, leaf pigment concentration, photosynthesis and leaf hyperspectral reflectance properties as affected by nitrogen supply. Plant Soil 2003, 257, 205-218. [CrossRef]

17. Delalieux, S.; van Aardt, J.; Keulemans, W.; Schrevens, E.; Coppin, P. Detection of biotic stress (Venturia inaequalis) in apple trees using hyperspectral data: Non-parametric statistical approaches and physiological implications. Eur. J. Agron. 2007, 27, 130-143. [CrossRef]

18. Jain, N.; Ray, S.S.; Singh, J.P.; Panigrahy, S. Use of hyperspectral data to assess the effects of different nitrogen applications on a potato crop. Precis. Agric. 2007, 8, 225-239. [CrossRef]

19. Blackburn, G.A.; Ferwerda, J.G. Retrieval of chlorophyll concentration from leaf reflectance spectra using wavelet analysis. Remote Sens. Environ. 2008, 112, 1614-1632. [CrossRef]

20. Thenkabail, P.S.; Smith, R.B.; De Pauw, E. Hyperspectral vegetation indices and their relationships with agricultural crop char-acteristics. Remote Sens. Environ. 2000, 71, 158-182. [CrossRef]

21. Abdel-Rahman, E.M.; Ahmed, F.B.; Berg, M.V.D. Estimation of sugarcane leaf nitrogen concentration using in situ spectroscopy. Int. J. Appl. Earth Obs. Geoinf. 2010, 12, S52-S57. [CrossRef]

22. Couture, J.J.; Serbin, S.P.; Townsend, P.A. Spectroscopic sensitivity of real-time, rapidly induced phytochemical change in response to damage. New Phytol. 2013, 198, 311-319. [CrossRef]

23. Agrios, G. Plant Pathogens and Disease: General Introduction. Encycl. Microbiol. 2009, 613-646. [CrossRef]

24. Curran, P.J. Remote sensing of foliar chemistry. Remote Sens. Environ. 1989, 30, 271-278. [CrossRef]

25. Jacquemoud, S.; Baret, F. PROSPECT: A model of leaf optical properties spectra. Remote Sens. Environ. 1990, 34, 75-91. [CrossRef]

26. Hunt, E.R.; Rock, B.N. Detection of changes in leaf water content using Near- and Middle-Infrared reflectances. Remote Sens. Environ. 1989, 30, 43-54.

27. Guyot, G. Optical Properties of Vegetation Canopies. Appl. Remote Sens. Agric. 1990, 1990, 19-43. [CrossRef]

28. Jones, H.G.; Vaughan, R.A. Remote Sensing of Vegetation: Principles, Techniques, and Applications; Oxford University Press: Oxford, $\mathrm{UK}, 2010$.

29. Haq, I.U.; Ijaz, S. Plant Disease Management Strategies for Sustainable Agriculture through Traditional and Modern Approaches; Springer Nature: Berlin/Heidelberg, Germany, 2020.

30. Arens, N.; Backhaus, A.; Döll, S.; Fischer, S.; Seiffert, U.; Mock, H.-P. Non-invasive Presymptomatic Detection of Cercospora beticola Infection and Identification of Early Metabolic Responses in Sugar Beet. Front. Plant. Sci. 2016, 7, 1377. [CrossRef]

31. Couture, J.J.; Singh, A.; Charkowski, A.O.; Groves, R.L.; Gray, S.M.; Bethke, P.C.; Townsend, P.A. Integrating Spectroscopy with Potato Disease Management. Plant. Dis. 2018, 102, 2233-2240. [CrossRef] [PubMed]

32. Oerke, E.-C.; Leucker, M.; Steiner, U. Sensory assessment of Cercospora beticola sporulation for phenotyping the partial disease resistance of sugar beet genotypes. Plant. Methods 2019, 15, 1-12. [CrossRef]

33. Gold, K.M.; Townsend, P.A.; Herrmann, I.; Gevens, A.J. Investigating potato late blight physiological differences across potato cultivars with spectroscopy and machine learning. Plant. Sci. 2020, 295, 110316. [CrossRef]

34. Mahlein, A.-K.; Steiner, U.; Dehne, H.-W.; Oerke, E.-C. Spectral signatures of sugar beet leaves for the detection and differentiation of diseases. Precis. Agric. 2010, 11, 413-431. [CrossRef]

35. Grisham, M.P.; Johnson, R.M.; Zimba, P.V. Detecting sugarcane yellow leaf virus infection in asymptomatic leaves with hyperspectral remote sensing and associated leaf pigment changes. J. Virol. Methods. 2010, 167, 140-145. [CrossRef]

36. Krezhova, D.; Petrov, N.; Maneva, S. Hyperspectral remote sensing applications for monitoring and stress detection in cultural plants: Viral infections in tobacco plants. SPIE Remote Sens. 2012, 8531, 85311H. [CrossRef]

37. Junges, A.H.; Ducati, J.R.; Lampugnani, C.S.; Almanca, M.A.K. Detection of grapevine leaf stripe disease symptoms by hyperspectral sensor. Phytopathol. Mediterr. 2018, 57, 399-406.

38. Feng, W.; Qi, S.; Heng, Y.; Zhou, Y.; Wu, Y.; Liu, W.; He, L.; Li, X. Canopy Vegetation Indices from In Situ Hyperspectral Data to Assess Plant Water Status of Winter Wheat under Powdery Mildew Stress. Front. Plant. Sci. 2017, 8, 1219. [CrossRef]

39. Thomas, S.; Kuska, M.T.; Bohnenkamp, D.; Brugger, A.; Alisaac, E.; Wahabzada, M.; Behmann, J.; Mahlein, A.-K. Benefits of hyperspectral imaging for plant disease detection and plant protection: A technical perspective. J. Plant. Dis. Prot. 2017, 125, 5-20. [CrossRef]

40. Hirshorn, S.; Jefferies, S. Final Report of the NASA Technology Readiness Assessment (TRA) Study Team; 2016. Available online: https:/ / ntrs.nasa.gov/ citations/ 20170005794 (accessed on 8 December 2021).

41. Lamichhane, J.R. Bacterial Diseases of Crops: Elucidation of the factors that lead to differences between field and experimental infections. Adv. Agron. 2015, 134, 227-246.

42. Heideman, M.T.; Johnson, D.H.; Burrus, C.S. Gauss and the history of the fast Fourier transform. Granul. Matter 1985, 34, $265-277$. [CrossRef]

43. Lee, W.; Alchanatis, V.; Yang, C.; Hirafuji, M.; Moshou, D.; Li, C. Sensing technologies for precision specialty crop production. Comput. Electron. Agric. 2010, 74, 2-33. [CrossRef]

44. Liu, Z.; Cheng, J.-A.; Huang, W.; Li, C.; Xu, X.; Ding, X. (Eds.) Hyperspectral Discrimination and Response Characteristics of Stressed Rice Leaves Caused by Rice Leaf Folder; Springer: Berlin/Heidelberg, Germany, 2012.

45. Thenkabail, P.S.; Smith, R.B.; De Pauw, E. Evaluation of narrowband and broadband vegetation indices for determining optimal hyperspectral wavebands for agricultural crop characterization. Photogramm. Eng. Rem. S. 2002, 68, 607-621. 
46. Zhang, Y.; Migliavacca, M.; Penuelas, J.; Ju, W. Advances in hyperspectral remote sensing of vegetation traits and functions. Remote Sens. Environ. 2021, 252, 112121. [CrossRef]

47. Nagler, P.; Daughtry, C.; Goward, S. Plant Litter and Soil Reflectance. Remote Sens. Environ. 2000, 71, 207-215. [CrossRef]

48. Mahlein, A.-K.; Oerke, E.-C.; Steiner, U.; Dehne, H.-W. Recent advances in sensing plant diseases for precision crop protection. Eur. J. Plant. Pathol. 2012, 133, 197-209. [CrossRef]

49. West, J.S.; Bravo, C.; Oberti, R.; Lemaire, D.; Moshou, D.; McCartney, H.A. The potential of optical canopy measurement for targeted control of field crop diseases. Annu. Rev. Phytopathol. 2003, 41, 593-614. [CrossRef] [PubMed]

50. Menesatti, P.; Antonucci, F.; Pallottino, F.; Giorgi, S.; Matere, A.; Nocente, F.; Pasquini, M.; D’Egidio, M.G.; Costa, C. Laboratory vs. in-field spectral proximal sensing for early detection of Fusarium head blight infection in durum wheat. Biosyst. Eng. 2013, 114, 289-293. [CrossRef]

51. Riefolo, C.; Antelmi, I.; Castrignanò, A.; Ruggieri, S.; Galeone, C.; Belmonte, A.; Muolo, M.; Ranieri, N.; Labarile, R.; Gadaleta, G.; et al. Assessment of the Hyperspectral Data Analysis as a Tool to Diagnose Xylella fastidiosa in the Asymptomatic Leaves of Olive Plants. Plants 2021, 10, 683. [CrossRef] [PubMed] 